\title{
A Brief Notes on the Meaning of Induced Pluripotent Stem Cell
}

\author{
Mariam M. Gerges, Heba N. Gad El-Hak* \\ Zoology Department, Faculty of Science, Suez Canal University, Ismailia, Egypt. \\ *Corresponding Author: Heba N. Gad El-Hak, Zoology Department, Faculty of Science, Suez Canal \\ University, Ismailia, Egypt.
}

\begin{abstract}
Reprogramming technology surprised many cell biologists at the beginning. Induced pluripotent stem cell (IPSCs) caused a real evolution in the cell biology; cells can be reprogrammed into their embryonic states whenever you need. The techniques are evolved enormously fast and today there are tremendous investments to develop robust and sensitive ways to generate ideal pluripotent cells. However, for obtaining the pluripotent lines, their subsequent differentiation and characterization, validated techniques and reagents in order to achieve high quality and safe progenitor cells must be conducted under controlled conditions. While those processes are helping a lot to solve the biggest problem of medicine, they are also pushing minds to think more deeply about health and treatment of illness. Yet, iPSCs would have profound implications for both basic research and clinical therapeutics by providing a patient-specific model system to study the disease pathway and test the effectiveness of pharmacological agents, as well as by providing an ample source of autologous cells that could be used for transplantation. This review act as a small note for the student and researcher beginner in understanding the meaning of stem cell and induced pluripotent stem cells.
\end{abstract}

Keywords: stem cell; induced pluripotent stem cells (iPSCs)

\section{INTRODUCTION}

Stem cells are undifferentiated cells defined by their abilities to self-renew and differentiate into mature cells(Polak and Bishop 2006). Stem cells found in fully developed tissues are defined as adult stem cells(Barker et al. 2010). The function of adult stem cells is the maintenance of adult tissue specificity by homeostatic cell replacement and tissue regeneration(Rojas-Ríos and González-Reyes 2014). Adult stem cells are presumed quiescent within adult tissues, but divide infrequently to generate a stem cell clone and a transiently-amplifying cell(Rojas-Ríos and González-Reyes 2014). The transiently-amplifying cells will undergo a limited number of cell divisions before terminal differentiation into mature functional tissue cells $(\mathrm{Ng}$ et al. 2014). The existence of adult stem cells has been reported in multiple organs; these include: brain, heart, skin, intestine, testis, muscle and blood, among others(Wagers and Weissman 2004). There are four adult stem cell populations: hematopoietic, mesenchymal, periodontal ligament-derived, and spermatogonial( $\mathrm{Ng}$ et al. 2013). Hematopoietic stem cells are the most characterized adult stem cell population. Which their function to generate all cell lineages found in mature blood (erythroid, myeloid and lymphoid) and to sustain blood production during the entire life of an animal. Hematopoietic stem cells can be characterized by positive selection of CD34, CD45, and CD133 markers and negative selection of CD31, CD105 and CD146 markers(Bryder et al. 2006). Adult bone marrow, umbilical cord blood and mobilized peripheral blood are sources of hematopoietic stem cells for transplantation in many blood-related diseases. Mesenchymal stem cells, also called marrow stromal cells, are another well-studied adult stem cell population. Mesenchymal stem cells were originally identified in the bone marrow, but have since been found in other systems such as adipose tissue, umbilical cord and menstrual blood. Mesenchymal stem cells differentiate into osteocytes, chondrocytes and adipocytes. Human mesenchymal stem cells can be characterized by the positive expression of CD29, CD44, CD73, CD90, CD105, CD146 and STRO-1, and the negative expression of CD31, CD34, CD45, CD49f and $\mathrm{CD} 133$ (Ng et al. 2013). Periodontal ligament, derived from the cranial neural crest, is a soft connective tissue embedded between the tooth root and the alveolar bone socket, supporting the teeth in situ and preserving tissue homeostasis. The periodontal ligament contains stem cell populations that can differentiate into cementum-forming cells or bone-forming cells. Periodontal ligament-derived stem cells are heterogeneous, composed of mesenchymal stem cells and putative neural crest cells. 
Therefore, human periodontal ligament-derived stem cell populations have not been characterized only by mesenchymal stem cell markers, but also by neural crest cell markers, such as p75, nestin, Slug and SOX10(Chen and Jin 2010). Testicular spermatogonial stem cells are the germ-line cells for spermatogenesis, an ongoing process throughout the lifespan of the male animals. They are unipotent in nature and continuously generate differentiating daughter cells for subsequent production of spermatozoa. Human spermatogonial stem cells can be purified by antibodies against cell surface markers CD9, CD49f and GPR125(Kanatsu-Shinohara and Shinohara 2013).

\section{TyPeS OF STEM CELLS}

The stem cell is divided into Pluripotent Embryonic stem cells, Multipotent Adult Tissue Stem Cells, Induced Pluripotent Stem Cells (iPSCs) (Ronaghi et al. 2010).

Pluripotent Embryonic stem cells are obtained from the inner cell mass of the blastocyst, a mainly hollow ball of cells that, in the human, forms three to five days after an egg cell is fertilized by a sperm, when growing these cells in special laboratory conditions, they retain the properties of embryonic stem cells. Embryonic stem cells are pluripotent, meaning they can give rise to every cell type in the fully formed body, but not the placenta and umbilical cord. These cells are incredibly valuable because they provide a renewable resource for studying normal development and disease, and for testing drugs and other therapies (Pedersen 1999).

Multipotent Adult Tissue Stem Cells come from different parts of the adult body. They are specific to a certain kind of tissue in the body: for instance, liver stem cells can regenerate liver tissue, and muscle stem cells can regenerate muscle fibers. But adult stem cells are limited to only become more of their specialized tissue, liver stem cells cannot make new muscle fibers, nor can muscle stem cells make new liver tissue. They are multipotent; i.e., can give rise to a number of related cell types, can renew themselves a number of times but not indefinitely. They include Mesenchymal stem cells (MSCs), Adipose-derived stem cells (ADSCs), Neural Stem Cells (NSCs), Hematopoietic Stem Cells (HSCs) and Cancer Stem Cells (CSCs) (Zammit and Beauchamp 2001).

Induced Pluripotent Stem Cells are pluripotent cells that are derived from adult tissue using new scientific technology. They share characteristics with embryonic stem cells in that they can become any cell type in the body. Reprogramming stem cells to create iPSCs involves some genetic manipulation, and this may cause some differences that are not present in cells that are already embryonic in nature (Bellin et al. 2012).

\subsection{Advantages and Disadvantages of Ips Cells}

\subsubsection{Advantage of Ips Cells}

iPS cells are considered a potential application in cell based therapy, one of its major advantages is the avoidance of immune rejection, since they are derived from a patient's own cells, as well as ethical issues associated with the use of human embryos. Furthermore, iPS cells are similar to ES cells in many aspects, including cell morphology, expression of pluripotency markers, long telomeres and capable to form embryoid bodies, teratoma, and viable chimeras (Chidgey et al. 2008).

Apart from use in cell-based therapy, iPS cells derived from diseased patients can serve as an effective model to understand the mechanisms of diseases. Recent advances in pluripotent stem cell biology now make it possible to generate human cardiomyocytes in vitro from both healthy individuals and from patients with cardiac abnormalities (Davis et al. 2011); Treatment of Sickle Cell Anemia Mouse Model with iPS Cells Generated from Autologous Skin (Hanna et al. 2007). A proofof-concept of using induced pluripotent stem cells (iPSCs) to generate human organ for transplantation was reported by researchers from Japan. Human 'liver buds' (iPSC-LBs) were grown from a mixture of three different kinds of stem cells (hepatocytes (for liver function) coaxed from iPSCs; endothelial stem cells (to form lines of blood vessels) from umbilical cord blood; and mesenchymal stem cells (to form connective tissue). This new approach allows different cell types from a self-organize into a complex organ, mimicking the process in fetal development. After growing in vitro for a few days, the liver buds were transplanted into mice where the 'liver' quickly connected with the host blood vessels and continued to grow. Most importantly, it performed regular liver functions including metabolizing drugs and producing liver-specific proteins. Further studies will monitor the longevity of the transplanted organ in the host body (ability to integrate or avoid rejection) and whether it will transform into tumors $(399 ; 400)$ Using this method, cells from one 
mouse could be used to test 1,000 drug compounds to treat liver disease, and reduce animal use by up to 50,000 (Gerbal-Chaloin et al. 2014).

iPSCs turn out to be a useful alternative to ESC research, they will avoid the most significant concerns in feminist ethics surrounding the issue because no egg donation used for iPSCs (Thompson 2013; Ellison and Meliker 2011; Braun and Schultz 2012).

\subsubsection{Disadvantages of Ips Cells}

However, use of iPS cells have several drawbacks and are mostly related to current reprogramming methods (González et al. 2011). Viral vectors employed for gene delivery have led to the integration of multiple viruses into iPS cell genomes, resulting in tumorigenesis due to genetic abnormalities in the cells (Hanna et al. 2007). Moreover, the efficiency of reprogramming of human iPS cells from fibroblasts is very low, approximately less than $0.02 \%$. The use of Myc gene as a reprogramming factor and/or the reactivation of a silenced Myc gene might cause iPS cells to become cancer cells (Kim et al. 2011). Recently, many published showed that the reprogramming process and the subsequent culture of iPS cells in vitro can induce genetic and epigenetic abnormalities in these cells (Pera 2011; Lister et al. 2011; Gore et al. 2011).

\section{CONCLUSION}

iPSCs are a very new discovery since only 2006, it is still to be determined iPS cells are equivalent to embryonic stem cells in all ways. Scientists are working hard on understanding the differences that may exist between embryonic stem cells and iPS cells, and we still have yet to determine which cell type will be the most useful for regenerative medicine. It is a good idea that everyone could have their own iPS cell line that could be used to make a personalized therapy product for themselves, but in practice this is very time consuming and expensive to do it on a personal basis. The process of generating an iPS cell line takes time and resources in a lab. To do so in a sterile and safe way in which the cells can be transplanted back into someone is even more expensive. It is also necessary that these cells undergo tests to ensure that they have not mutated or changed in any detrimental way through the reprogramming process.

On the other hand, the generation of the cells in has already been performed in Embryonic stem cell therapies in proper ways, and the expensive tests can be performed on a single stem cell line, rather than a different line for every individual. It is possible that one day iPSCs may prove to be equivalent to embryonic stem cells (ESCs) and could be used in the same way we use ESCs now.

\section{REFERENCES}

[1] Barker N, Bartfeld S, Clevers H (2010) Tissue-resident adult stem cell populations of rapidly selfrenewing organs. Cell stem cell 7 (6):656-670

[2] Bellin M, Marchetto MC, Gage FH, Mummery CL (2012) Induced pluripotent stem cells: the new patient? Nature reviews Molecular cell biology 13 (11):713

[3] Braun K, Schultz S (2012) Oöcytes for research: Inspecting the commercialization continuum. New Genetics and Society 31 (2):135-157

[4] Bryder D, Rossi DJ, Weissman IL (2006) Hematopoietic stem cells: the paradigmatic tissue-specific stem cell. The American journal of pathology 169 (2):338-346

[5] Chen F-M, Jin Y (2010) Periodontal tissue engineering and regeneration: current approaches and expanding opportunities. Tissue Engineering Part B: Reviews 16 (2):219-255

[6] Chidgey AP, Layton D, Trounson A, Boyd RL (2008) Tolerance strategies for stem-cell-based therapies. Nature 453 (7193):330

[7] Davis RP, van den Berg CW, Casini S, Braam SR, Mummery CL (2011) Pluripotent stem cell models of cardiac disease and their implication for drug discovery and development. Trends in Molecular Medicine 17 (9):475-484. doi:https://doi.org/10.1016/j.molmed.2011.05.001

[8] Ellison B, Meliker J (2011) Assessing the risk of ovarian hyperstimulation syndrome in egg donation: implications for human embryonic stem cell research. The American Journal of Bioethics 11 (9):22-30

[9] Gerbal-Chaloin S, Funakoshi N, Caillaud A, Gondeau C, Champon B, Si-Tayeb K (2014) Human induced pluripotent stem cells in hepatology: beyond the proof of concept. The American Journal of Pathology 184 (2):332-347

[10] González F, Boué S, Belmonte JCI (2011) Methods for making induced pluripotent stem cells: reprogramming a la carte. Nature Reviews Genetics 12 (4):231 
[11] Gore A, Li Z, Fung H-L, Young JE, Agarwal S, Antosiewicz-Bourget J, Canto I, Giorgetti A, Israel MA, Kiskinis E, Lee J-H, Loh Y-H, Manos PD, Montserrat N, Panopoulos AD, Ruiz S, Wilbert ML, Yu J, Kirkness EF, Belmonte JCI, Rossi DJ, Thomson JA, Eggan K, Daley GQ, Goldstein LSB, Zhang K (2011) Somatic coding mutations in human induced pluripotent stem cells. Nature 471:63. doi:10.1038/nature09805

[12] https://www.nature.com/articles/nature09805\#supplementary-information

[13] Hanna J, Wernig M, Markoulaki S, Sun C-W, Meissner A, Cassady JP, Beard C, Brambrink T, Wu L-C, Townes TM, Jaenisch R (2007) Treatment of Sickle Cell Anemia Mouse Model with iPS Cells Generated from Autologous Skin. Science 318 (5858):1920. doi:10.1126/science.1152092

[14] Kanatsu-Shinohara M, Shinohara T (2013) Spermatogonial stem cell self-renewal and development. Annual review of cell and developmental biology 29:163-187

[15] Kim JS, Choi HW, Choi S, Do JT (2011) Reprogrammed pluripotent stem cells from somatic cells. International journal of stem cells 4 (1):1-8

[16] Lister R, Pelizzola M, Kida YS, Hawkins RD, Nery JR, Hon G, Antosiewicz-Bourget J, O’Malley R, Castanon R, Klugman S, Downes M, Yu R, Stewart R, Ren B, Thomson JA, Evans RM, Ecker JR (2011) Hotspots of aberrant epigenomic reprogramming in human induced pluripotent stem cells. Nature 471:68. doi:10.1038/nature09798

[17] https://www.nature.com/articles/nature09798\#supplementary-information

[18] Ng TK, Fortino VR, Pelaez D, Cheung HS (2014) Progress of mesenchymal stem cell therapy for neural and retinal diseases. World journal of stem cells $6(2): 111$

[19] Ng TK, Pelaez D, Fortino VR, Greenberg J, Cheung HS (2013) Pluripotent Adult Stem Cells: A Potential Revolution in Regenerative Medicine and Tissue Engineering. In: Pluripotent Stem Cells. IntechOpen,

[20] Pedersen RA (1999) Embryonic stem cells for medicine. Scientific American 280 (4):68-73

[21] Pera MF (2011) The dark side of induced pluripotency. Nature 471:46. doi:10.1038/471046a

[22] Polak JM, Bishop AE (2006) Stem cells and tissue engineering: past, present, and future. Annals of the New York Academy of Sciences 1068 (1):352-366

[23] Rojas- Ríos P, González- Reyes A (2014) Concise review: The plasticity of stem cell niches: a general property behind tissue homeostasis and repair. Stem Cells 32 (4):852-859

[24] Ronaghi M, Erceg S, Moreno- Manzano V, Stojkovic M (2010) Challenges of stem cell therapy for spinal cord injury: human embryonic stem cells, endogenous neural stem cells, or induced pluripotent stem cells? Stem cells 28 (1):93-99

[25] Thompson C (2013) Good science: The ethical choreography of stem cell research. MIT Press,

[26] Wagers AJ, Weissman IL (2004) Plasticity of adult stem cells. Cell 116 (5):639-648

[27] Zammit PS, Beauchamp JR (2001) The skeletal muscle satellite cell: stem cell or son of stem cell? Differentiation 68 (4-5):193-204.

Citation: Heba N. Gad El-Hak.., et al., " A Brief Notes on the Meaning of Induced Pluripotent Stem Cell ",International Journal of Research Studies in Zoology, vol. 5, no. 1, p. 14-17, 2019.

DOI: http://dx.doi.org/10.20431/2454-941X.0501003

Copyright: (C) 2019 Authors. This is an open-access article distributed under the terms of the Creative Commons Attribution License, which permits unrestricted use, distribution, and reproduction in any medium, provided the original author and source are credited. 